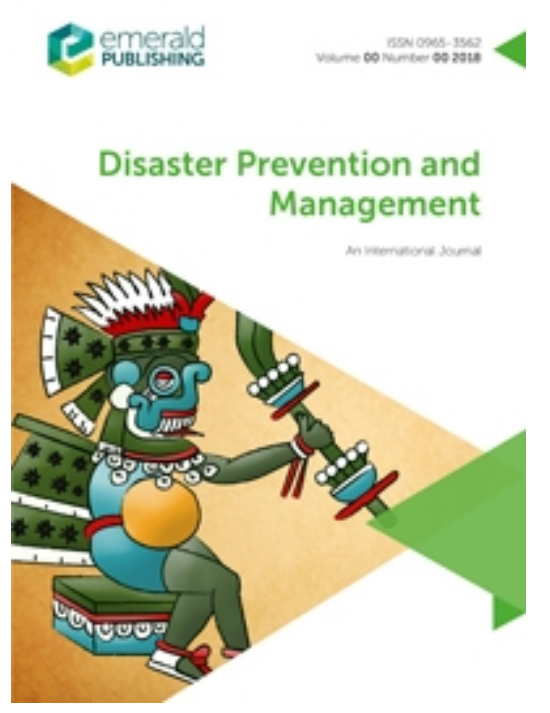

\title{
Development of disaster risk reduction policy in Thailand
}

\begin{tabular}{|r|l|}
\hline Journal: & Disaster Prevention and Management \\
\hline Manuscript ID & DPM-08-2019-0244.R4 \\
\hline Manuscript Type: & Research Paper \\
\hline Keyword: & $\begin{array}{l}\text { policy learning, restrictive-expansive policy learning, community-based } \\
\text { disaster risk reduction, Thailand, Disaster risk governance, Disaster Risk } \\
\text { Reduction }\end{array}$ \\
\hline \multicolumn{2}{|l}{} \\
\hline
\end{tabular}

\section{SCHOLARONE}

Manuscripts 


\title{
Development of disaster risk reduction policy in Thailand
}

\begin{abstract}
This exploratory study discusses the policy learning process of the development of disaster risk reduction (DRR) policy. The paper discusses how DRR has and has not developed in Thailand through the two major disasters: the 2004 Indian Ocean Tsunami and the 2011 Great Flood. The information was collected by documentary analysis to gain a historical and critical understanding of the development of the system and policy of DRR in Thailand. Additionally, key stakeholders' interviews were undertaken to supplement the analysis. The paper demonstrates Thailand's DRR development has been 'reactive' rather than 'proactive', being largely directed by global DRR actors. Further, the application of the 'restrictive-expansive policy learning' model, which identifies different dimensions of policy learning, reveals the Thai government's policy learning was of a mixed nature. The paper concludes by reflecting on the usefulness of the model in analysing DRR policy process.
\end{abstract}

\section{Keywords}

disaster risk reduction; disaster risk governance; policy learning; restrictiveexpansive policy learning; community-based disaster risk reduction; Thailand 


\section{Introduction}

The purpose of this exploratory study is to discuss the policy learning process of the development of disaster risk reduction (DRR) in Thailand. The paper depicts how DRR has and has not developed through the two major disaster experiences: the 2004 Indian Ocean Tsunami and the 2011 Great Flood. The Asian continent has experienced natural hazards of all types in the past 20 years. For geophysical disasters, Asia accounts for $85 \%$ of all affected people, $78 \%$ of reported economic damage, as well as $62 \%$ of all occurrences and $69 \%$ of deaths. For climate-related disasters, $86 \%$ of affected populations lived in flood- and storm-prone Asia (UNISDR/CRED, 2017). Thailand is ranked as the seventh most flood-prone country in the world (UNDP, 2011).

In developing countries, where an operative DRR system may not have been established yet, strengthening DRR at the grassroots level, i.e. community-based, is considered critical (JICA, 2019). The literature suggests Thailand fits into this description (ADPC, 2015; JICA, 2008), although the country joined the upper-middle-income countries in 2015 (JICA, 2018). In this context, the paper discusses the emergence of the policy discourse of community-based (CB) DRR in Thailand.

The novel feature of the study is the utilisation of the "restrictive-expansive policy learning' model (Hodgson and Spours, 2016) developed in the field of education in analysing policy development. The tentative conclusion is policy learning in this national case is that policy learning could be characterised as largely restrictive, given that Thailand's DRR development was very much directed by global DRR leaders.

\section{Methodology}

\section{Case study approach}

In Thailand, the total population of about 63 million resides in a geographically and environmentally diverse landscape, having mountainous areas in the north, the Menam Chao Phraya delta in the central part, the Andaman Sea to the west and the Gulf of Thailand to the south. The tropical climate means there is a rainy season from May to October (ADRC, 2008). Historically, Thai people have cohabited with their environmental and meteorological conditions benefiting from water and at the same time, accepting flood risks (ADPC, 2015). There were two watershed moments that threatened such a way of living - the Indian Ocean Tsunami of 2004 and the Great Flood of 2011 which are the focus of this paper.

Qualitative case study approaches are empirical enquiries that enable an investigation of a phenomenon within its real-life context with the use of multiple datasets (Yin, 2012). This case study of Thailand explored how the development of DRR had been constructed through major disaster experiences and external drivers. The study was guided by the following four research questions:

1. Who are the major actors in the development of DRR in Thailand?

2. What are the watershed moments historically in the development of DRR?

3. How has 'community-based DRR' come into the policy domain?

4. What are the strength and weakness of the restrictive-expansive policy learning model in analysing the development of DRR policy?

Literature review and policy analysis were conducted to understand the historical development of the system and policy of DRR in Thailand. The interrogated official 
sources include the relevant websites of the Thai government and those of international organisations (e.g. UNDRR), the key intervention project reports issued by international agencies (e.g. Asian Disaster Preparedness Center), and academic literature. All sources reviewed were in English. No Thai language literature was reviewed. To compensate for this limitation, empirical data was collected - six interviews with key stakeholders (three academic experts, two national policy-makers, an activist and a community leader) were undertaken in Bangkok in December 2018. They provided supplementary information that contextualised the literature review and policy analysis. The sample was small due to limited resources, but served the purpose of obtaining diverse views on the development of DRR. The interview data were analysed thematically to identify the key themes to respond to the research questions.

\section{Literature review}

Policy learning in disaster risk governance

Disaster risk governance (DRG) was addressed in both the Hyogo Framework for Action 2005-2015: Building the Resilience of Nations and Communities to Disasters (HFA) and the Sendai Framework for DRR 2015-2030 (SFDRR) (Raju and da Costa, 2018). The emphasis on strengthening governance for DRR through the enhancement of national, regional and international cooperation has remained unchanged. The 'renewed' stress in SFDRR, however, is its 'voluntary' nature and 'light' approach treating DRG to be achieved 'through consensus and broad incentives' (Raju and da Costa, 2018, 280). In doing so, SFDRR advocates an 'integrated' (UNISDR, 2015) approach to DRR, which requires the involvement of various stakeholders and the inclusion of DRR perspectives in all sectors and systems. The call for 'inclusive risk governance' (Schweizer and Renn, 2019) has become mainstream, which takes into account 'the broader legal, political, economic and social contexts in which a risk is evaluated and managed' (Klinke and Renn, cited in Schweizer and Renn, 2019, 857). Integrated/inclusive approaches will be discussed further in later sections.

Lebel and Lebel (2018) examine policy narratives in investigating the governance of the recent floods in Thailand. There are established theories on policy process, such as the Advocacy Coalition Framework and the Narrative Policy Framework. The former delves into the causal driver for political behaviour, while the latter considers policy narratives to measure their power and influence (Shanahan et al., 2011). Lebel and Lebel's work belongs to the latter group, inquiring 'why' the Thai government repeated similar ineffective responses to the floods, which was criticised by national and international stakeholders. Their argument is it was the institutional traps (selfreinforcing processes which tend to maintain institutions important for flood management in a configuration that is likely to undermine the capacity of a society to cope with major floods)' (Lebel and Lebel, 2018, 616-617) that prevented the governance from improving. The authors conclusion could be viewed as a limited approach to 'policy learning' by the Thai authorities, although they do not necessarily discuss the concept itself.

\section{The restrictive-expansive model}

This paper aims to tease out the Thai government's approach to policy learning through the application of Hodgson and Spours' (2016) restrictive-expansive policy learning model that drew on the conceptual work of Fuller and Unwin $(2003 ; 2010)$ in relationship to work-based learning. The Hodgson and Spours adaptation was initially developed to analyse upper secondary education policy in the UK and was chosen here on the basis of 
its multi-dimensional perspective, offering potential new insights into the policy analysis of DRR in Thailand.

According to this model, Governments' ability to learn depend on the following four dimensions.

'Policy motivation'

In the school education policy context, restrictive learning refers to the policy-makers' major motivation being the improvement of 'education systems for competitive economic and political gain'. For policy learning to be expansive, policy-makers would utilise international comparisons aiming for 'mutual understanding' and 'shared knowledge' in improving own system by prioritising 'collaboration' over 'competition'.

'Governance structure and forms of exchange'

Restrictive policy learning is associated with policy-making involving a small number of politicians. On the other hand, in the case where a wide range of stakeholders who may hold 'broader learning motives' without political ambitions are involved, expansive learning can be achieved.

'International comparison and system selection'

A number of authors have pointed out the danger of borrowing 'the best' educational practice elsewhere (Steiner-Khamsi, 2012; Morris, 2012; Raffe, 2011). Policy-makers choose such restrictive measures because of their persuasive power, i.e. 'visible to publics', and their controllable nature, i.e. by using, for example, consultants. More expansive approaches to Learning from other systems should be done much more cautiously, considering 'common issues' and assessing 'comparable contexts' to meet local needs.

'Historical understanding'

Expansive learning is based on 'policy memory', while restrictive learning can result from 'policy amnesia' (Higham and Yeomans, 2007; Pollitt, 2008). With the reflection of policy history involving a range of stakeholders, a healthy policy-cycle - continuity, evaluation, revision - might be achieved.

\section{Major DRR actors}

For the purpose of analysing Thailand's development of DRR, this paper treats United Nations Office for Disaster Risk Reduction (UNDRR), Asian Disaster Preparedness Center (ADPC) and Japan International Cooperation Agency (JICA) as major DRR actors in the context of Thailand. This is because Thai DRR experts interviewed repeatedly referred to them as 'key partners', even though other national and international organisations such as the Red Cross have offered aids and interventions to Thailand.

Established in 1999, UNDRR (2020a) has played a pivotal role in developing and disseminating the concept and practice of DRR. In 2005, the Second World Conference on Disaster Reduction adopted HFA. A series of large-scale disasters followed: e.g. the Sichuan Earthquake in 2008, the Haiti Earthquake in 2010 (The Guardian, 2016). UNDRR (2020a) responded by creating the UN Plan of Action on DRR for Resilience, stressing the integration of DRR initiatives in national systems. The 2016 revised Plan of Action linked DRR agendas closely with the Sustainable Development Goals (SDGs) (UNDRR, 2020a). One of the agencies leading this strand is the United Nations 
Development Programme (UNDP). Currently, UNDRR (2020b) has a responsibility to support the implementation, follow-up and review of SFDRR.

ADPC (2019) was established in 1986 is an intergovernmental organisation between the nine-member countries in Asia. The activist interviewed referred to ADPC as having 30 years of technical knowledge on DRR. ADPC (2019) operates under six strategic themes, including risk governance, climate resilience and preparedness. ADPC also has decades of experience in promoting CBDRR, collaborating with a range of partners. The academics, policy-makers and activist interviewed spoke about ADPC as a 'donor' and a 'supporter' for Thailand.

JICA contributes to international cooperation, as well as the development of the Japanese and global economy (JICA, 2019). Japan has accumulated knowledge and expertise in DRR as one of the severest disaster-prone countries in the world (ANONYM, 2016). As one policy-maker interviewed indicated, JICA had acted as an advocate for the mainstreaming of DRR in Thailand. JICA (2019) emphasises the support in post-disaster phases for increased preparedness for future disasters. This is an application of the 'Build Back Better' principle stressed in SFDRR.

The paper now turns to discuss Thailand's two watershed moments in the development of DRR, including the emergence of the policy discourse of 'communitybased DRR (CBDRR)'.

\section{Global and local response to the 2004 Indian Ocean Tsunami}

Scale and impact of the Indian Ocean Tsunami

On 26 December 2004, the tsunami occurred off the Sumatra Island and affected a large area of the South and Southeast Asia, which was one of the most devastating tsunamis in world history. Thailand experienced record fatalities and economic damage: the death toll of 5,395, 2,817 missing in the southern provinces along the Andaman Sea rim (DDPM, 2015; Sato, 2009). According to UNICEF, the number of children who lost a parent amounts to 1,100 , and those in temporary accommodation were more than 2,000. A total of 26 schools in southern provinces were destroyed or partly destroyed (UNICEF cited in Sato, 2009). The consequent economic loss was US\$ 399.78 million (ADRC, 2008). Bangar Province experienced the largest damage because of its flat and wide coast. Apart from some pine trees, hardly any obstacles existed, resulting in a failure to weaken the wave. The tsunami hit in the middle of the peak season when the beaches were full of tourists, seasonal workers and fishermen (Sato, 2009). The following comment made by a Thai official shows the state of people's awareness towards tsunami at the time: 'we couldn't have responded better because we didn't know what "tsunami" was' (Tanaka, 2009 , 147). As the academics interviewed recalled, the tsunami was the event that prompted the government to embark on comprehensive DRR policy-making.

\section{Global DRR discourse - pledging to take actions on DRR}

In the following January in 2005, 168 member countries adopted HFA with an increased endorsement after witnessing the Indian Ocean Tsunami. HFA was a paradigm change in two senses: the emphasis became pre-disaster prevention and preparedness, rather than post-disaster response and recovery; an 'action' plan, not a theory-based document (Takahashi, 2009). HFA offered five priority areas for action as guiding principles and practical tools for each country to develop its own 'strategic national action plan (SNAP)'. Prioritising DRR to build 'a culture of safety and resilience' through capacity 
development was stressed (ADPC and APG, 2013; UN/ISDR, 2005). HFA was a global pledge to take actions for reducing disaster risks.

By the mid-2000s, DRR actors had established a consensus that DRR was a condition for addressing development challenges. 'Disasters impact on all aspects of development, undermining efforts to achieve the Millennium Development Goals' (DFID, 2004, 19). DRR actors began promoting a prior investment in DRR as a risk reduction measure (JICA, 2019). Many governments of developing countries have not yet built effective DRR systems, and Thailand was one of them in 2004, as one of the expert academics interviewed indicated. There was a gap between the global-level DRR discourse and the situation in Thailand.

Thai government response - establishing a DRR system with the support of global actors At the time of the tsunami, the only disaster-related laws existed in Thailand were the 1979 Civil Defence Act and the 1999 Fire Prevention and Suppression Act. The Department of Disaster Prevention and Mitigation (DDPM) had been set up in 2002 in the Ministry of Interior as the main government agency for coordinating DRR activities, but it was not yet in full operation as a new agency. 'Natural hazards', let alone 'tsunami', were undefined. The 2004 tsunami prompted the government to organise legal structures first. The new Disaster Prevention and Mitigation Act replaced the above two laws in 2007, stipulating the National Disaster Prevention and Mitigation Committee chaired by the Prime Minister who was responsible for DRR policy-making (Tanaka, 2009; JICA, 2008; Nakamura, 2006). At the local level, the Provincial Disaster Prevention and Mitigation Committee and Bangkok Metropolitan Committee were formed.

In this process, the Thai government asked the Government of Japan for cooperation. The 'Technical Cooperation Project on Capacity Development in Disaster Management in Thailand' project helped central and local governments and communities to improve their DRR capabilities (JICA, 2008). In Phase 1, for example, Thailand's first White Paper on Disaster Prevention and Mitigation was created. There was an attempt to engage communities through pilot schemes and to introduce disaster education at school. Phase 2 developed national disaster prevention and mitigation plans, as well as human resource development curricula. JICA's approach thus aimed to build a sustainable DRR model in Thailand with a focus on capacity development (Takahashi, 2009).

ADPC (2015) also intervened in setting up early warning systems in the regions affected by the 2004 tsunami. In collaboration with UNDP and DDPM, ADPC built the technical and operational capacities in the communities for the use of the warning systems. Another ADPC/UNDP intervention was the founding of the Disaster Prevention and Mitigation Academy in 2005 (ADRC, 2008). They aimed to provide local leaders with courses on disaster prevention and response procedures.

The SNAP on DRR 2010-2019 was also completed by DDPM in this period. With assistance from ADPC and funding support from UNISDR, DDPM (2009) developed four DRR strategies corresponding to the disaster cycle. Endorsed in March 2009 as a national guideline and implementation strategic plan, the SNAP addressed DRR to be mainstreamed in every aspect of the government planning (ADPC and APG, 2013). 
Nevertheless, in the midst of establishing a DRR system in 2011, Thailand experienced the 'most catastrophic flood' (DDPM, 2015, 4) in its history. This was the second watershed moment for the development of DRR in Thailand.

\section{Global and local response to the 2011 Great Flood}

Scale and impact of the Great Flood

Thailand had experienced large-scale flooding in 1942, 1983, 1995 and 2000, but the 2011 Great Flood was on a different scale - 'one in 50-100 year event' (World Bank cited in Poapongsakorn and Meethom, 2013). The World Bank reports that the total economic damage of US $\$ 46.5$ billion of the Thai Great Flood (ADPS and APG, 2013). Given the domestic economic growth in 2011 in Thailand was only $0.1 \%$, the World Bank expressed concern of the reduction of economic growth potential and the sustainability of the development path (Kawamori, 2012).

Beginning in July, the flooding had spread to 64 out of 77 Provinces by January 2012, involving 5,247,125 households and resulting in 1,026 fatalities (DDPM, 2015; ADRC, 2008). The flooding affected Northern, North Eastern and Central Thailand along the Mekong and Chao Phraya River basins, as well as the capital Bangkok. A total of $73.7 \%$ of the affected households were flooded for about 26 days, having the water level reaching up to 88 centimetres and $18 \%$ of the affected households evacuated for the average of 39 days (Kawamori, 2012). In some areas, flood water did not recede for 70 days (World Bank cited in Poapongsakorn and Meethom, 2013).

A number of studies were conducted to analyse the causes of such extensive damage. Meteorologically, the rainfall between January and October 2011 was the highest on record; five tropical cyclones including large-scale Haima and Nok Ten between June and October bringing heavy rain across the country; it exceeded the capacity of the dams in the North and Northeast provinces and major rivers inundating plains; Bangkok and surrounding areas were affected by high sea levels in the Gulf of Thailand (Otomo, 2015; Poapongsakorn and Meethom, 2013; Kawamori, 2012). Geographically, Thai rivers being low-angled meant the process of inundation was gradual, but once inundated, water could not escape for months (Kawamori, 2012). From the economic viewpoint, the misuse of the land for the purpose of industrialisation in what had used to be flood plains worsened the floods. Bangkok was the only city with a 'zoning law', which was revised prioritising business interests allowing access to the canals and flood plains (Poapongsakorn and Meethom, 2013).

Man-made errors in flood management were also identified, e.g. the operations of major reservoirs being out-dated, the delay in controlling water gates due to politicians' own interests, ageing flood protection infrastructure, coordination problems between the central and the local administrations. Research indicated a lack of social and educational efforts in DRR: $51.1 \%$ of the population in the submerged areas did not know how to swim; 45\% did not know how to call an ambulance; hardly anyone knew about the emergency service of boats and helicopters existed (Phaiboon, 2012 cited in Kawamori, 2012). The political turmoil at the time did not help the response and recovery stage either. Following the 2006 coup d'état, the conflict between the Shinawatra brothers continued. The general election of August 2011 led Yingluck Shinawatra to a new Prime Minister, but instability continued during the Great Flood, which prevented response measures from being implemented (Otomo, 2015). 
In 2011, other parts of the world were also experiencing severe disasters - a series of floods in Australia, the Christchurch Earthquake and the Tohoku disaster. DRR actors and governments were under pressure in need of new solutions to increasing risks across the world.

Global DRR discourse - the necessity of integrated approaches and 'all-of-society' engagement

DRR experts began questioning the conception of 'disasters' being 'location-specific', discovering 'cascading effects' deriving from 'the global interconnected system' (Okazumi and Nakasu, 2015; Shimizu and Clark, 2015). Pescaroli and Alexander (2015, 65) define 'cascading disasters' as 'extreme events, in which cascading effects increase in progression over time and generate unexpected secondary events of strong impact'. Kelman (2018) identifies the 2010 Eyjafjallajökull eruption which closed many European airports and the 2011 Great Japan East Earthquake and Tsunami which destroyed a nuclear power plant as typical examples of cascading disasters. Disasters having cascading effects have reinforced the notion that DRR must be discussed and planned collaboratively and internationally. In parallel, enhancing 'soft' or non-structural measures to increase preparedness in people was stressed. One of the soft means became CBDRR. For example, in Japan, a new initiative was introduced in 2013 to encourage every community to create a CBDRR plan (Cabinet Office, 2014). Such 'integrated' and 'inclusive' approaches based on joined-up working amongst all stakeholders became focal in the global DRR discourse. These principles were subsequently stipulated in SFDRR. In Thailand, as one academic interviewed mentioned, it was after the 'crisis' of 2011 that a need for CBDRR was recognised.

Thai government response - towards 'all-of-society' engagement guided by global leaders

The Thai Government response the flood disaster was criticised by the public, as well as by DRR actors (Otomo, 2015; ADPC and APG, 2013). First, flood monitoring and forecasting was short-term, resulting in insufficient readiness. When the heavy rainfall began, inaccurate early warning confused the public, delaying their actions. The flood database was being developed but unsystematically, resulting in limited use. More than 40 government agencies working on water and flood management created coordination gaps. All of these were related to the fact that instead of the existing Disaster Prevention and Mitigation Act, the Government applied the Prime Minister's Policy to manage the disaster (ADPC and APG, 2013). DDPM (2015b) later acknowledged that the new approach with the SNAP had not yet been familiarised by government agencies.

In response to the public and international criticisms, the Thai Government created a Flood Management Master Plan. JICA continued to support in this process. Their main involvement was the construction of flood gates and rehabilitation of national roads in the Ayutthaya region (JICA, 2012). The Government had 'relied upon' JICA recommendations on infrastructural investment and flood management in developing the Master Plan (ADPC and APG, 2013). Even though 'a Single Command authority' and 'integrate the participation of stakeholders' (ADPC and APG, 2013, 9) were mentioned in the Plan, as Poapongsakorn and Meethom (2013) point out, its focus depended on physical infrastructure without significant non-structural measures being proposed.

In the wake of the disaster, the UNDP implemented an intervention project that 'mainstreamed' non-structural approaches in 'Strengthening disaster management 
capacities in Thailand 2012-15' (Government of Thailand and UNDP, 2012). Its recommendations included a need to strengthen staff and institutional capacities of DDPM to respond to large-scale disasters, to systematise a means to determine the scale and severity of a disaster and to develop communication strategies for promoting DRR to the public. The Thai government updated the National Disaster Prevention and Mitigation Plan into the National Disaster Risk Management Plan, incorporating 'disaster level criteria', addressing 'DRR' and taking crossministerial approaches with 'comprehensive strategies' (DDPM, 2015a). The Plan indicated 'focusing on DRR' by strengthening 'local, individual and community capacity' (DDPM, 2015a, 17). 'Applying an integrated emergency management system' which should be 'systematic' and 'multisectoral' was also emphasised (DDPM, 2015a, 18). The Plan presented a holistic strategic framework envisaging all phases of the disaster cycle and various types of disaster. Every relevant agency was asked to create its action plan and budget to support the implementation of the Plan (ADPC and APG, 2013).

ADPC's $(2015,12)$ 'community-focused projects' were 'gaining particular momentum' after the Great Flood and implemented across Thailand. DDPM began drawing attention to the positive aspects of CBDRR in the National Disaster Risk Management Plan: 'this practice [CBDRR] has made a significant contribution to ensure that the people and their community are better prepared for diverting or coping with the effects of natural hazards with the least expected loss and damage of life and property' (DDPM 2015a, 63). The proposals included setting up a natural hazard learning centre and the National Institute for Disaster Management Capacity Development, which would offer DRR knowhow to government officials and the public (DDPM, 2015a). The Plan also stipulated the responsibility of every ministry in promoting DRR. For example, for the Ministry of Education, curricula at all levels should include disaster-related subjects and raising the public's DRR awareness (DDPM, 2015a). Some intention of the Thai government to strengthen integrated working and engage 'all-of-society' could be identified in the policy document.

\section{The policy learning process of the Thai government}

This final section highlights the government's intentions and actions using the restrictiveexpansive policy learning model.

\section{Policy motivation}

Given that increased and interconnected disaster risks are widely understood by DRR actors and governments (UNISDR, 2015), 'collaboration' and 'cooperation' amongst them are considered necessary in improving national systems in preparing for disasters. 'Mutual understanding' and 'shared knowledge' are strongly promoted through multistakeholder events such as the International Disaster and Risk Conference (IDRC, 2019). In this light, in comparison with educational policy-making, expansive learning is considered more necessary in the area of DRR.

In the case of Thailand, the initial construction of a comprehensive national DRR system was very much triggered by the first watershed event of the 2004 tsunami and guided by global DRR actors. HFA's call for DRR 'actions' drove the Thai government to produce the SNAP and invest in a DRR system. Responding to HFA's priority area of the building of 'a culture of safety and resilience' in communities was a step too far for the government being occupied by setting up an overall legal and policy structure for DRR. There were, in fact, a number of CBDRR initiatives implemented after the tsunami 
(e.g. Pananont et al, 2015; Pananont and Srisomboon, 2014), but the point to note is that the Thai government did not consider CBDRR as a national policy at this stage.

Discussion and research around CBDRR were increasing at the international level at the time of the Great Flood, which was the second watershed event in Thailand. The role of global actors remained significant during and after the flood. Subsequently, SFDRR recommended that governments should consolidate an 'integrated' DRR approach and promote 'all-of-society' engagement. The Thai government reflected this in the 2015 National Disaster Risk Management Plan, clearly promoting CBDRR. It can be speculated that such policy was influenced by the global discourse on the emphasis on CBDRR.

Governance structures and forms of exchange

In establishing a national DRR system swiftly after the 2004 tsunami, the Thai government sought interventions from global DRR actors. Such decisions were probably taken executively, given the urgency of the disaster response. Between 2004 and 2011, a legal and governance structure was arranged, and the SNAP was introduced. Despite this, as Marks and Lebel (2016) and Ng (2016) argue, the decentralisation of power and resources is 'incomplete' and 'fragmented', leaving policy structures to be incoherent at all levels. 'These governance weaknesses visibly materialized during the 2011 floods (Marks and Lebel, 2016, 64).'

One assessment report on the population response of the 2011 flood revealed a complex picture of the interplay between public participation and political trust (ADPC and APG, 2013). During the flood, community participation was considered limited. this was not the result of a lack of interest by the public, but because of the conflict between communities and local governments, stemming from 'the distrust of the public against the authority that lacked political transparency (ADPC and APG, 2013, 20)'. Communities did hold forums and hearings, but 'their outcomes were not necessarily being reflected in the decision-making process, resulting in public frustration (ADPC and APG, 2013, 12)'. This was arguably why public networks and platforms, such as the Indonesian National Platform for DRR in Indonesia, did not exist in Thailand, even though there were a number of informal groups and personal links addressing DRR challenges. The report suggests forming partnerships to enable community participation in implementing CBDRR (ADPC and APG, 2013). It could be concluded there was a limited development of integrated and inclusive DRG.

\section{International comparison and system selection}

In this dimension, the Thai government's policy learning appears to have been restricted throughout the experiences of the 2004 and 2011 disasters. The leadership of UNISDR has been prominent due to their responsibility in implementing and monitoring the international DRR strategy frameworks. Regional leaders such as ADPC and JICA already have rich knowledge and expertise that they aim to disseminate to as many countries as possible. Consequently, from Thailand's viewpoint, the 'best practice' offered by the global actors was the way forward, without much critical reflection. One of the academic experts interviewed indicated that Thailand still did not have their own DRR and CBDRR - all had been provided by those DRR leaders. 
Following the 2011 Great Flood, the Thai Government began to officially acknowledge the significance of CBDRR. There was a mention of 'comprehensive strategies' combining both hard and soft measures and the development of an integrated DRR system. Nevertheless, criticisms persisted that the Government's priority was clearly of large-scale infrastructure projects, such as the construction of floodways and water reservoirs, with an allocated budget of more than US\$ 12 billion. As Nikomborirak and Ruenthip (2013, no page) argue: 'Very little attention has been paid to the developing [of] the much needed "software" that will be required to effectively manage the new infrastructure.' It could be seen that the Thai Government's approach to developing DRR policy remained largely unchanged over the periods of the two watershed events which were largely driven by global DRR actors. Academic interviewees confirmed that an integrated DRR system and society engagement, and hence CBDRR, was hardly identifiable in Thailand, as of December 2018. It would seem, therefore, that effective learning from past experience was adversely affected by particular government policy priorities.

\section{Conclusion}

The two watershed events in 2004 and 2011 had a massive impact on the lives of the Thai people, the country's development and triggered the shaping and reshaping of the DRR system in the country. The question at the centre of this paper is the nature of the policy learning of the Thai Government. By applying the different dimensions of the 'restrictive/expansive' model, it can be concluded that policy learning was mixed but mostly restrictive. In the dimensions of governance structures and forms of exchange, international comparison and system selection and historical understanding, the Thai Government's policy approach was more at the restrictive end of the spectrum, while the Government's policy motivation could be interpreted as on the expansive end.

The model can help deconstruct which dimension of the learning process a government has/has not achieved well. Thus, the different dimensions of the model have the potential to enable a deeper understanding of governments' policy processes in relation to global agendas such as DRR and SDGs.

At the same time, the restrictive/expansive model would benefit from elaboration in different case contexts. For example, classifying 'policy motivation' as 'competition/collaboration' does not necessarily suit interconnected policy agendas such as DRR. Aiming for 'inclusive' DRG, various stakeholders and sectors are increasingly collaborating. Rather than 'competition/collaboration', the spectrum of 'passive/proactive' might better suited to capture the state of the government's motivation. A government may be passive in engaging in the policy development of DRR, following global leaders' initiatives resulting in restrictive policy learning, like it was the case in Thailand. A government's political will for proactive engagement in mainstreaming DRR is a requisite for integrated and inclusive DRG.

The model suggests that for policy-making to be effective, all dimensions of the policy learning need to be towards the expansive end of the spectrum. In the case of DDR, this points to the need for expansive approaches to be explored in developing integrated and inclusive DRG. The present DRR discourse highlights the importance of integrating all sectors and structures and stakeholders' inclusive engagement. Besides the governance dimension, this paper argues that addressing other dimensions of policy motivation, 
international comparison and historical reflection might also help actualise integrated and inclusive approaches to DRR. However, rigorous analyses of more cases using this adapted model is required in arriving at this conclusion.

\section{Acknowledgements}

This work was supported by the UCL Global Engagement Fund 2018-19 [grant number 539596]. I would like to express my great appreciation to Dr Puntita Tanwattana from the Environmental Research Institute, Chulalongkorn University and her students, Atcha Waitayachewa and Thawatchai Palakhamarn for their generous assistance in my organising the fieldwork in Bangkok. I am also grateful for all the interviewees who agreed to share their knowledge and experience with me. This piece of study could not have completed without their cooperation.

\section{References}

ADPC (2019), "ADPC at a glance", available at: http://www.adpc.net/igo/contents/adpcpage.asp?pid=2 (accessed 24 May 2019).

ADPC (2015) "Empowering communities \& strengthening resilience: Thailand", available at: http://www.adpc.net/igo/category/ID927/doc/2015-cGw3AM-ADPCADPC_Empowering_communities_Thailand.pdf (accessed 24 May 2019).

ADPC and APG (HelpAge International and AADRRER Partnership Group) (2013), "Assessment of Disaster Management, Planning, Policies and Responses in Thailand", available at: https://www.helpage.org/silo/files/assessment-of-disaster-managementplanning-policies-and-responses-in-thailand-.pdf (accessed 24 May 2019).

Alexander, D. (2018), “A magnitude scale for cascading disasters", International Journal of Disaster Risk Reduction, Vol. 30 Part B, pp. 180-185.

Asian Disaster Reduction Center (ADRC) (2008), "Information on DRR of the member countries: Thailand", available at: https://www.adrc.asia/nationinformation.php?NationCode=764\&Lang=en\&NationN um=09 (accessed 24 May 2019).

Cabinet Office, Government of Japan (2014), "Community Disaster Management Plan Guidelines", available at: http://www.bousai.go.jp/kyoiku/pdf/guidline.pdf (accessed 24 June 2019).

DDPM (2015a), "National Disaster Risk Management Plan", available at: http://www.disaster.go.th/upload/download/file_attach/584115d64fcee.pdf (accessed 24 May 2019).

DDPM (2015b), "Thailand: National progress report on the implementation of HFA (2013-2015)", available at: https://www.preventionweb.net/files/41674_THA_NationalHFAprogress_201315.pdf (accessed 24 June 2019).

DDPM (2009), Strategic National Action Plan on Disaster Risk Reduction 2010-2019, Agricultural Cooperate Federation of Thailand, Bangkok.

DFID (2004), "Disaster risk reduction: a development concern: a scoping study on links between disaster risk reduction, poverty and development", available at: https://www.unisdr.org/files/1070_drrscopingstudy.pdf (accessed 20 May 2019).

Fuller, A. and Unwin, L. (2003), "Learning as apprentices in the contemporary UK workplace: creating and managing expansive and restrictive participation", Journal of Education and Work, Vol. 16 No. 4, pp. 407-425. 
Fuller, A. and Unwin, L. (2010), “Knowledge workers' as the new apprentices: the influence of organisational autonomy, goals and values on the nurturing of expertise", Vocations and Learning, Vol. 3 No. 3, pp. 201-222.

Government of Thailand and UNDP (2012), "Strengthening disaster management capacities in Thailand 2012-2015", available at: http://www.undp.org/content/dam/undp/documents/projects/THA/Prodoc_sthing_di saster_mgt_cap_092012_FFINAL.pdf (accessed 20 June 2019).

The Guardian (2016), “A decade of disasters", available at: https://www.theguardian.com/global-development/datablog/2011/mar/18/worlddisasters-earthquake-data (accessed 20 June 2019).

Higham, J. and Yeomans, D. (2007), "Policy memory and policy amnesia in 14-19 education: learning from the past?", in Raffe, D. and Spours, K. (Eds.), Policy-making and Policy Learning in 14-19 Education, Bedford Way Papers, Institute of Education, London.

Hodgson, A. and Spours, K. (2016), "Restrictive and expansive policy learning challenges and strategies for knowledge exchange in upper secondary education across the four countries of the UK", Journal of Education Policy, Vol. 31 No. 5, pp. 511525.

IDRC (2019), “IDRC”, available at: https://idrc.info/ (accessed 20 May 2019).

JICA (2019), "Disaster risk reduction", available at: https://www.jica.go.jp/english/our_work/thematic_issues/disaster/overview.html (accessed 27 May 2019).

JICA (2018), "JICA Annual Report", available at: https://www.jica.go.jp/english/publications/reports/annual/2018/c8h0vm0000dxws0g -att/2018_all.pdf (accessed 27 May 2019).

JICA (2012), "JICA Annual Report", available at: https://www.jica.go.jp/english/publications/reports/annual/2012/c8h0vm00002qe6vjatt/all.pdf (accessed 27 May 2019).

JICA (2008), "The project on capacity development in disaster management in Thailand: final report", available at: http://open_jicareport.jica.go.jp/pdf/11898244_01.pdf (accessed 27 May 2019).

Kawamori, M. (2014), "The Great Flood in Thailand and social security", International Social Welfare Studies, National Institute of Population and Social Security Research, Vol. 188, pp. 15-23.

Kelman, I. (2018), "Connecting theories of cascading disasters and disaster diplomacy", International Journal of Disaster Risk Reduction, Vol. 30 Part B, pp. 172-179.

Klinke, A. and Renn, O. (2010), "Risk governance: contemporary and future challenges", in Eriksson, J., Gilek, M. and Rudén, C. (Eds), Regulating Chemical Risks European and Global Challenges, Springer, Dordrecht, pp. 9-27.

Lebel, L. and Lebel, P. (2018), "Policy narratives help maintain institutional traps in the governance of floods in Thailand", International Journal of Water Resources Development, Vol. 34 No. 4, pp. 616-631.

Marks, D. and Lebel, L. (2016), "Disaster governance and the scalar politics of incomplete decentralization: fragmented and contested responses to the 2011 Floods in central Thailand", Habitat International, Vol. 52, pp. 57-66.

Morris, P. (2012), 'Pick'n'mix, select and project; policy borrowing and the quest for 'World Class' schooling: an analysis of the 2010 Schools White Paper', Journal of Education Policy, Vol. 27 No. 2, pp. 89-107. 
Nakamura, T. (2006), "Disaster reduction governance: building a resilient society." Monthly JICA, November 2006, available at: https://www.jica.go.jp/publication/monthly/0611/02.html (accessed 12 July 2019).

Nakasu, T., Okazumi, T. and Shimizu, Y. (2012), "Development of Flood Disaster Preparedness Indices (FDPI) in Thailand: focus on the cases of Ubon Rachathani and Hat Yai", Annual Thai Research, Vol. 12, pp. 65-80.

$\mathrm{Ng}$, S. (2016), "Governance beyond the government: responding to a reactionary flood governance regime in Ayutthaya, Thailand", Habitat International, Vol. 52, pp. 1119.

Nikomborirak, D. and Ruenthip, K. (2013), "Policy brief: history of water resource and flood management in Thailand", available at: http://tdri.or.th/wpcontent/uploads/2013/11/Policy-Brief-01-History-of-Flood-Management-inThailand.pdf (accessed 12 July 2019).

Okazumi, T. and Nakasu, T. (2015), "Lessons learned from two unprecedented disasters in 2011 - Great East Japan Earthquake and Tsunami in Japan and Chao Phraya River flood in Thailand", International Journal of Disaster Risk Reduction, Vol. 13, pp. 200-206.

Otomo, Y. (2015), "Disaster prevention and mitigation policies in Thailand", Journal of Asia-Pacific Studies, Asia-Pacific Research Center, Waseda University Vol. 24, pp. 109-121, available at: http://hdl.handle.net/2065/45349 (accessed 24 May 2019).

Pananont P. and Srisomboon R. (2014), "2004 Tsunami in Southern Thailand, lessons learned for the Thai communities", in Kontar, Y., Santiago-Fandiño, V. and Takahashi T. (Eds.), Tsunami Events and Lessons Learned. Advances in Natural and Technological Hazards Research, vol 35, Springer, Dordrecht, pp. 399-416.

Pananont P., Srisomboon R., Kongkaew W. and Kriwichai P. (2015), "Accomplishments in the south coastal Thai communities after the 2004 tsunami in the restoration process, a case study in Ranong Province", in Santiago-Fandiño V., Kontar Y. and Kaneda Y. (Eds.), Post-Tsunami Hazard. Advances in Natural and Technological Hazards Research, vol 44, Springer, Cham, pp. 73-95.

Pescaroli, G. and Alexander, D. (2015), "A definition of cascading disasters and cascading effects: going beyond the "toppling dominos" metaphor." Global Risk Forum Davos planet@risk, Vol. 2 No. 3, pp. 58-67, available at: https://planetrisk.org/index.php/pr/article/download/208/309 (accessed 12 July 2019).

Phaiboon, S. and National Statistics Office (2012), "The 2011 Great Flood - lessons from the experience", Health System Research Institute, Nonthaburi.

Poapongsakorn, N. and Meethom, P. (2013), "Impact of the 2011 floods, and flood management in Thailand", ERIA Discussion Paper Series, ERIA-DP-2013-34, available at: http://www.eria.org/ERIA-DP-2013-34.pdf (accessed 24 June 2019).

Pollitt, C. (2008), Time, Policy, Management: Governing with the Past, OUP, Oxford.

Raffe, D. (2011), "Policy borrowing or policy learning? How (not) to improve education systems", CES Briefing Centre for Educational Sociology, University of Edinburgh No. 57, available at: http://www.ces.ed.ac.uk/PDF\%20Files/Brief057.pdf (accessed 24 June 2019).

Raju, E. and da Costa, K. (2018), “Governance in the Sendai: a way ahead?", Disaster Prevention and Management, Vol. 27 No.3, pp. 278-291.

Sato, H. (2009), "The Sumatra Earthquake, Tsunami in Thailand (2004) - diverse phenomena of tsunami and mutual assistance", World Trend, Institute of Developing Economies, Japan External Trade Organization Vol. 15 No.6, pp. 23-26, available at: from http://hdl.handle.net/2344/00004739 (accessed 17 June 2019). 
Schweizer, P.-J. and Renn, O. (2019), "Governance of systemic risks for disaster prevention and mitigation", Disaster Prevention and Management, Vol. 28 No.6, pp. 854-866.

Shanahan, E. A., Jones, M. D. and McBeth, M. K. (2011), "Policy narratives and policy processes", Policy Studies Journal Vol. 39 No.3, pp. 535-561.

Shimizu, M. and Clark, C. L. (2015), "Interconnected risks, cascading disasters and disaster management policy: a gap analysis", Global Risk Forum Davos planet@risk Vol. 3 No. 2, available at: https://planet-risk.org/index.php/pr/article/view/199/407 (accessed 12 July 2019).

Steiner-Khamsi, G. (2012), "Understanding policy borrowing and lending: building comparative policy studies", in Steiner-Khamsi, G. and Waldow, F. (Eds.), World Yearbook of Education: Policy Borrowing and Lending in Education, Routledge, New York, pp. 3-17.

Tanaka, T. (2009), "Challenges for international cooperation in disaster preparedness/reduction: a case-study of JICA's activities in Thailand after the Indian Ocean Tsunami disaster", Forum of International Development Studies, Departmental Bulletin Paper, Nagoya University Vol. 38, pp. 137-156.

UNDP (2011), "Disaster risk management post disaster needs assessment for sustainable recovery Thailand floods 2011. UNDP Internal Report on DRR-PDNA", available at: http://www.niems.go.th/en/Upload/File/255511281805228004_KCkv8gyKOTkHBlz 7.pdf (accessed 20 May 2019).

UNDRR (2020a), "History", available at: https://www.undrr.org/about-undrr/history (accessed 3 March 2020).

UNDRR (2020b), “Our Work", available at: https://www.undrr.org/about-undrr/ourwork (accessed 3 March 2020).

UNISDR (2015), “Sendai Framework for Disaster Risk Reduction 2015-2030”, available at: https://www.preventionweb.net/files/43291_sendaiframeworkfordrren.pdf (accessed 20 May 2019).

UNISDR (n.d.), "From a reactive to proactive then people centered approach to DRR", available

at:

https://www.unisdr.org/files/49574_hfacelebrationreport7082015verdana.pdf (accessed 12 July 2019).

UN/ISDR (2005), "Strategic National Action Plan for DRR: an action plan for governments and civil society organisations to implement HFA", available at: https://www.adrc.asia/acdr/2006seoul/documents/008a_Session2_presen/0_1_ISDR_ Chung.pdf (accessed 20 May 2019).

UNISDR and the Centre for Research on the Epidemiology of Disasters (CRED) (2017), "Economic losses, poverty \& disasters: 1998-2017", available at: https://www.preventionweb.net/files/61119_credeconomiclosses.pdf (accessed 24 June 2019).

World Bank (2012), Thai Flood 2011: Rapid Assessment for Resilient Recovery and Reconstruction Planning, The World Bank, Bangkok.

Yin, R.K. (2012), Applications of case study research. 3rd ed, SAGE, Thousand Oaks, CA.

ANONYM (2016), "Disaster preparedness, adaptive politics and lifelong learning: a case of Japan", International Journal of Lifelong Education, Vol. 35 No. 6, pp. 629-647. 
Table 1. Dimensions of restrictive and expansive policy learning in education (Hodgson and Spours 2016)

Dimension

1. Policy motivation structures and forms of exchange

3. International comparison and system selection

4. Historical understanding
Restrictive

Competitive - designed to improve one's own system in relation to economic globalisation and national politics

Centralised and exclusive to national policy-makers

Borrowing of 'best practice' from 'successful systems' in order to compete with a dominant global education reform model

Culture of constant policy innovation, focus on the new within a climate of 'policy amnesia'
Expansive

Collaboration - designed to develop understanding to improve one's own system and contribute to international knowledge base

Decentralised and partnership-based with mediating layers of discussion that involve a range of stakeholders including practitioners

Identification of common issues and 'good practice' in comparable contexts to assist with discussion of national problems and policy options

Understanding of national system histories through the exercise of 'policy memory' and reflection 
Table 1: Dimensions of restrictive and expansive policy learning in education (Hodgson and Spours 2016)]

Dimension

1. Policy motivation

2. Governance structures and forms of exchange

3. International comparison and system selection

\section{Historical} understanding
Restrictive

Competitive - designed to improve one's own system in relation to economic globalisation and national politics

Centralised and exclusive to national policy-makers

Borrowing of 'best practice' from 'successful systems' in order to compete with a dominant global education reform model

Culture of constant policy innovation, focus on the new within a climate of "policy amnesia'
Expansive

Collaboration - designed to develop understanding to improve one's own system and contribute to international knowledge base

Decentralised and partnershipbased with mediating layers of discussion that involve a range of stakeholders including practitioners

Identification of common issues and 'good practice' in comparable contexts to assist with discussion of national problems and policy options

Understanding of national system histories through the exercise of 'policy memory' and reflection 